\title{
RELAÇÕES ENTRE O SISTEMA DE CRÉDITO E O AMBIENTE CONSTRUÍDO URBANO NOS ESTADOS UNIDOS
}

\author{
the relations between the credit system and the urban built environment in United States
}

\author{
Daniel de Mello Sanfelici*
}

\begin{abstract}
Resumo
A última crise econômica nos Estados Unidos despertou um interesse renovado pelos vínculos entre o sistema de crédito e a produção e consumo do ambiente construído urbano no capitalismo contemporâneo. Esse trabalho pretende examinar as transformações sofridas pelo sistema de financiamento habitacional nos Estados Unidos nas últimas três décadas como ilustrativas de um processo mais abrangente, fundamentalmente atrelado à ascensão do neoliberalismo, de financeirização do ambiente construído urbano. Dois aspectos dessa transformação merecem destaque ao longo da exposição. Um primeiro remete à importância crucial do Estado em promover um ambiente regulatório propício à securitização de hipotecas. Um segundo aspecto diz respeito ao desafio colocado aos bancos e instituições financeiras pelo processo de desintermediação, que transformou o sistema de crédito americano na década de 1980. O trabalho conclui tentando situar teoricamente as transformações observadas no contexto da financeirização da economia capitalista.
\end{abstract}

Palavras-Chave: Financeirização, Sistema de crédito habitacional, Ambiente construído urbano.

\begin{abstract}
The last economic crisis in the United Stated sparked growing interest in the links between the credit system and the production and consumption of the urban built environment in contemporary capitalism. This paper attempts to examine the changes occurred in US housing finance system in the last three decades as an illustration of the broader process of financialization of the urban built environment. Two aspects of this change are emphasized throughout the article. The first refers to the key role of the state in promoting a regulatory framework for the securitization of mortgages. The second refers to the challenge of financial disintermediation faced by banks and other financial institutions. This challenge ended up by transforming the American credit system in the 1980s. In the concluding section, we have attempted to theoretically situated these transformations against the background of the financialization of the economy.
\end{abstract}

Key words: Financialization; Housing finance system; Urban built environment.

\begin{abstract}
Resumen
La última crisis económica en Estados Unidos ha despertado un renovado interés por los vínculos entre el sistema de crédito, y la producción y el consumo del ambiente construido urbano en el capitalismo contemporaneo. Este trabajo pretende examinar las transformaciones sufridas por el sistema de financiamiento habitacional en Estados Unidos durante las últimas tres décadas. Estas son entendidas como ilustrativas de un proceso más amplio, fundamentalmente asociado al ascenso del neoliberalismo, de financiarización del ambiente construido urbano. Dos aspectos de esta transformación merecen ser destacados especialmente. El primero remite a la importancia del Estado para promover un ambiente regulatorio propicio para la securititzación de hipotecas. El segundo aspecto refiere al desafio provocado a los bancos e instituciones financieras por el proceso de deintermediación, que transformo el sistema de crédito americano en la década de 1980. En la conclusión de este trabajo se situará teoricamente las transformaciones observadas en el contexto de financiarización de la economía capitalista.
\end{abstract}

Palabras clave: Financiarización, Sistema de crédito habitacional, Ambiente construído urbano.

(*) Doutorando da Pos-Graduação em Geografia Humana da Universidade de São Paulo - Av. Prof. Lineu Prestes, 338, CEP 05.508-000, São Paulo (SP), Brasil, Tel: (+ 55 11) 3091-3769 - danielsanfelici@gmail.com. 


\section{INTRODUÇÃO}

A repentina erupção da crise econômica mundial na esteira do colapso do mercado de hipotecas nos Estados Unidos em 2007 suscitou um interesse renovado, na Geografia e em outras ciências sociais, pelas relações entre o sistema de crédito e a produção e consumo do ambiente construído urbano (AALBERS, 2008; 2009; SASSEN, 2008; GOTHAM, 2009; NEWMAN, 2009; IMMERGLUCK, 2009). Diversas preocupações entrelaçam-se nessa renovação do interesse pela problemática, mas há uma percepção compartilhada, reforçada pelos efeitos da crise econômica mundial, de que a forma como se estrutura o sistema de crédito do ponto de vista da produção e consumo do ambiente construído tem consequências não apenas para o problema do acesso à moradia, mas também afeta de inúmeras maneiras, através da produção de determinados padrões espaciais das cidades, as condições de acesso das famílias aos benefícios produzidos pela aglomeração urbana. Tendo em vista essas preocupações, o que a crise econômica americana explicitou, com toda a devastação econômica e social, foi a fragilidade de um sistema de crédito habitacional cuja espinha dorsal consiste no mercado de capitais.

Esse trabalho pretende examinar a maneira como o crédito habitacional, enquanto peça importante do sistema de crédito, modificou-se ao longo dos últimos trinta anos nos Estados Unidos, adquirindo feições que sintonizam com o avanço do neoliberalismo no seio da sociedade e da economia americanas. Argumenta-se que o empenho do Estado em criar um ambiente regulatório e institucional propício à transformação do ambiente construído urbano em um ativo financeiro responde a pressões da esfera financeira para a abertura de novas fronteiras de investimentos para capitais excedentes. Essas pressões intensificaram-se ao longo dos últimos quinze anos, originando, na década de 2000, um mercado de hipotecas de alto risco que, através de bancos de investimento e outras instituições financeiras em Wall Street, atraiu investidores localizados em diversos países do mundo.

A primeira seção desse artigo examina o surgimento e evolução inicial do mercado secundário de hipotecas nos Estados Unidos. Após um breve panorama histórico do desenvolvimento do financiamento habitacional nos Estados Unidos a partir dos anos 1930, a seção enfoca as mudanças introduzidas no mercado de hipotecas nos anos 1960 e 1970 pelo governo federal como passos importantes na direção de uma transformação estrutural do sistema de crédito imobiliário no país, sobretudo no decorrer dos anos 1980. Essa transformação, conforme será visto, liga-se a mudanças mais abrangentes no sistema financeiro americano.

A segunda seção discorre acerca da metamorfose no crédito imobiliário com o advento das hipotecas de alto risco (subprime), que iniciaram um incremento já na década de 1990, mas que experimentaram um crescimento exponencial no decorrer da bolha imobiliária dos anos 2000. Duas circunstâncias foram identificadas como cruciais para explicar essa aceleração nas hipotecas subprime: a primeira diz respeito aos problemas enfrentados pela economia americana desde o final da década de 1990, quando estourou a bolha das empresas de tecnologia, interrompendo um processo de recuperação dos patamares de lucro e da produtividade na indústria; a segunda vincula-se às transformações dos mecanismos de segregação racial nos Estados Unidos, sugerindo um movimento da exclusão financeira para a expropriação financeira.

O trabalho conclui tecendo comentários acerca das consequências desse modelo financeirizado de crédito habitacional, procurando situá-lo no contexto mais amplo das transformações, não restritas aos Estados Unidos, na relação entre o sistema financeiro e a produção do ambiente construído urbano.

\section{O ESTADO E A CRIAÇÃO DE UM MERCADO SECUNDÁRIO DE HIPOTECAS}

A questão da circulação do capital no ambiente construído coloca uma série de obstáculos que requerem a intervenção do Estado e de um complexo sistema financeiro para que sejam supe- 
rados. Por essa razão, do ponto de vista da investigação teórica, esse problema exige uma atenção diferenciada.

O nó da questão reside na compatibilização entre os horizontes temporais da reprodução do capital, atrelados à necessidade interminável de aceleração do tempo de rotação, e a produção e o consumo do ambiente construído, tipicamente um processo lento em virtude da natureza intrínseca do valor de uso em questão. Esse problema foi abordado, em trabalho já clássico, por David Harvey (1999). A solução, segundo Harvey, repousa sobre a criação de um abrangente aparato político-institucional capaz de coordenar e regulamentar um sistema financeiro suficientemente sofisticado para possibilitar a transferência dos capitais excedentes gestados no circuito primário - a produção de mais-valia - para o que o autor denominou circuito secundário - a produção e consumo do ambiente construído. Esse aparato desenvolve-se em uma esfera com relativa independência em relação ao circuito primário, envolvendo diferentes agentes econômicos que ocupam distintas posições em relação ao circuito como um todo. Nas palavras de David Harvey:

As necessidades peculiares da circulação do capital através do ambiente construído resultaram na evolução de um tipo especial de sistema de produção-realização que define novos papéis para os agentes econômicos. Proprietários de terra recebem renda, incorporadores imobiliários recebem incrementos de renda com base em melhoramentos, construtoras auferem lucro empresarial, entidades financeiras provém capital-dinheiro em troca de juros ao mesmo tempo que são capazes de capitalizar qualquer forma de rendimento que flui do ambiente construído na forma de capital fictício (o preço do imóvel), e o Estado pode usar os tributos (atuais ou futuros) como suporte para investimentos que o capital não pode ou não irá se encarregar, mas que ampliam a base para a circulação local do capital (HARVEY, 1999, p. 395).

Com efeito, a circulação do capital pelo ambiente construído coloca obstáculos tão significativos que é quase inviável sua efetivação sem a presença ostensiva do Estado em proporcionar múltiplas formas de incentivo ao capital privado. Um exemplo claro disso é oferecido pelo crédito habitacional, que ao longo do século XX, em muitos países, adquiriu o formato de contratos com prazos de 20 a 30 anos, lastreados pelo imóvel e com reduzido pagamento de entrada (de 10\% a $40 \%$ do valor do país, dependendo do país) (GREEN \& WACHTER, 2005). De fato, não fosse pelo Estado regulamentar o volume das reservas bancárias que deve compulsoriamente ser alocado ao crédito habitacional, bem como oferecer garantias tanto aos contratos de hipoteca quanto aos correntistas dos bancos, dificilmente esse investimento atrairia o interesse dos bancos. Isso porque um empréstimo desse gênero fere os interesses da valorização do capital ao aprisionar o capital a um investimento de baixa liquidez com determinada rentabilidade por um período de tempo extremamente longo, durante o qual o investidor (o banco) poderá perder oportunidades de investimento mais rentáveis ou enfrentar surtos inflacionários que corroem as parcelas da hipoteca. É por isso também que, em muitos casos (o Brasil é um deles), os bancos públicos historicamente tiveram presença mais significativa nesse tipo de empréstimo.

O estabelecimento de um sistema de crédito habitacional nos Estados Unidos ilumina essa centralidade do papel do Estado. Diversas características dos contratos de hipoteca prevalentes na maior parte do século XX nos Estados Unidos possuem origem em sucessivas políticas de estímulo à casa própria introduzidas pelo governo americano. Embora nem sempre seja possível identificar claras transições no avanço das políticas de crédito habitacional, há um consenso quanto à importância das reformas implementadas na década de 1930, medidas que devem sua existência, em grande parte, ao esforço do governo americano em superar a crise econômica iniciada em 1929.

As primeiras medidas adotadas pelo governo Franklin D. Roosevelt tiveram como meta resgatar mutuários em risco de inadimplência, principalmente através da criação, em 1933, da Home Owners Loan Corporation (HOLC), empresa pública encarregada de implementar um programa de aquisição e refinanciamento de hipotecas em atraso no portfólio de entidades de poupança e empréstimo (chamadas Savings and Loans, embora na época ainda fossem conhecidas por Building and Loan). 
Em seguida, em 1934, através do National Housing Act, o governo criou a Federal Housing Authority (FHA), órgão governamental incumbido de segurar contratos de hipoteca. Essa medida foi de importância ímpar para incentivar o crescimento na oferta de crédito habitacional nas décadas subsequentes. Além disso, a FHA tornou padrão os contratos de hipoteca de longo prazo (30 anos), juros fixos e cobrindo $80 \%$ do valor do imóvel que se tornariam característicos no restante do século XX. Segundo Dan Immergluck,

o seguro de hipotecas da FHA aumentou a oferta de crédito imobiliário e tornou possível contratos de financiamento previsíveis, de baixo risco e de longo prazo, reduzindo os custos efetivos de empréstimo e diminuindo os riscos dos mutuários oriundos de incertezas acerca da disponibilidade e custo do crédito no futuro (IMMERGLUCK, 2009, p. 35).

Essas medidas inauguradas nos anos 1930, que se somam a outras posteriores como o auxílio aos veteranos da II Guerra Mundial para obter crédito habitacional a baixo custo, provocaram um aumento significativo na proporção de famílias proprietárias de sua moradia. Elas também desempenharam papel central no padrão de urbanização disperso que caracterizou a expansão econômica do pós-guerra. Com efeito, é necessário entender essas políticas, como já foi sugerido acima, como parte do pacote keynesiano de estímulo à retomada do crescimento econômico após o colapso dos anos 1930 (WALKER, 1981; HARVEY, 1989).

Durante a expansão do pós-guerra até meados de 1980, o sistema de crédito habitacional permaneceu com uma formatação hoje considerada mais tradicional, amparado nas garantias oferecidas pelo governo federal e alicerçado em instituições como entidades de poupança e empréstimo (Savings and Loan) e bancos comerciais. Essas instituições financeiras mantinham as hipotecas como ativos em seu balanço contábil, em vez de transferi-las a terceiros (investidores), além de possuírem um raio geográfico de operação tipicamente regional.

O crescimento da securitização de hipotecas ao longo dos anos 1980 representa um divisor de águas na forma como se estrutura o sistema de crédito habitacional nos Estados Unidos, que se distanciou paulatinamente do modelo descrito resumidamente nos parágrafos anteriores. A securitização consiste no processo de transferência de ativos como hipotecas para investidores do mercado financeiro, em vez de sua permanência no portfólio do originador (os bancos comerciais ou as entidades de poupança e empréstimo, entre outros). Os investidores adquirem um título (security, origem do termo securitização) cujo fluxo de renda é gerado pela amortização e os juros do conjunto de hipotecas que lastreiam o título. As razões para essa transformação devem muito, também, a medidas implementadas pelo governo federal entre o final da década de 1960 e início da década de 1970: a transformação da agência governamental Federal National Mortgage Association (conhecida também como Fannie Mae) em uma empresa de capital aberto com a meta de adquirir hipotecas e vender títulos lastreados por hipotecas no mercado financeiro; a criação de sua principal concorrente no mercado de hipotecas securitizadas, a Federal Home Loan Mortgage Corporation (conhecida como Freddie Mac); e a permissão à primeira para adquirir hipotecas "privadas" (ou seja, hipotecas sem o seguro da Federal Housing Authority (FHA)). Essas reformas constituíram o primeiro passo para o crescimento da securitização de hipotecas a partir dos anos 1980.

Entretanto, ainda que essas reformas tenham estabelecido uma atmosfera propícia à transformação do financiamento imobiliário, as condições objetivas para o crescimento da securitização ainda não estavam dadas. Estas últimas vieram a emergir no início da década de 1980 nos Estados Unidos. Conforme a exposição de Gary Dymski (2009), nos anos 1980 os bancos comerciais e as entidades de poupança e empréstimo (S\&L) sofreram sucessivos reveses em virtude do que se tornou convenção designar por desintermediação, o que ocasionou dificuldades para o financiamento imobiliário nos moldes tradicionais. Entende-se por desintermediação a prática de empresas e famílias de acessar de modo direto o mercado financeiro, solapando o papel dos bancos em intermediar cadeias de poupança e de crédito. As empresas, por exemplo, passaram a se financiar 
através da emissão de títulos, tais como debêntures, ofertados diretamente para investidores. As famílias, por sua vez, por meio de instituições como fundos de pensão, passaram a canalizar suas poupanças para o mercado financeiro, em vez de mantê-las em um depósito bancário como a caderneta de poupança. Esse fenômeno atingiu com especial intensidade as entidades de poupança e empréstimo (S\&L), o que levou o governo americano a sancionar medidas, entre 1980 e 1985, para flexibilizar as opções de investimento disponíveis a essas entidades, que até então defrontavam-se com severas restrições legais a investimentos fora do ramo de crédito habitacional (GOTHAM, 2009). A maioria delas diminuiu drasticamente o volume de empréstimo habitacional (Figura 1), e muitas entraram em processo de falência poucos anos depois como resultado de investimentos malogrados (DYMSKI, 2009).

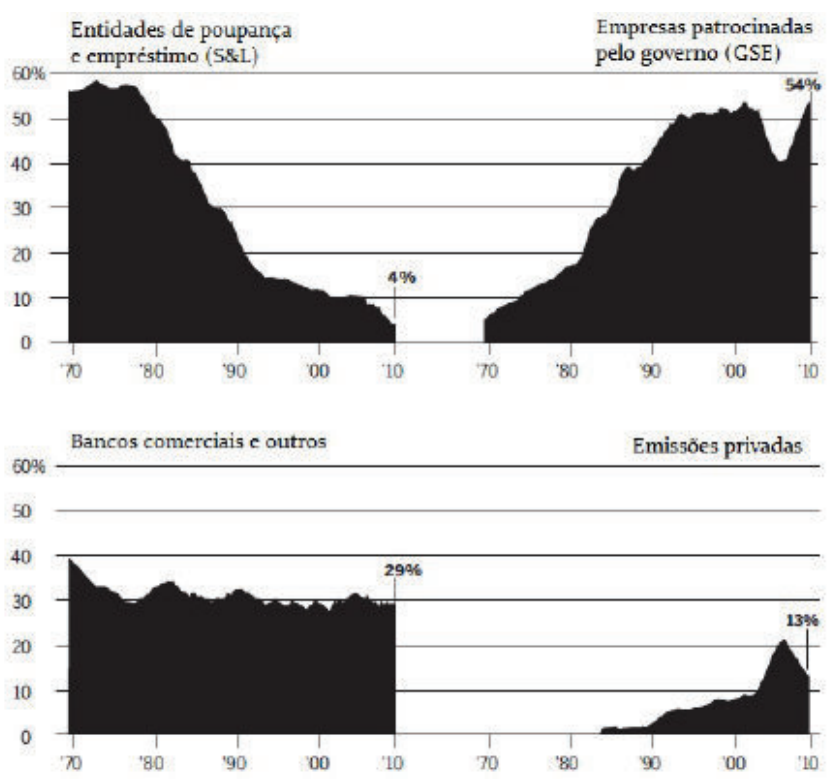

Figura 1 - Fonte de recursos para empréstimos hipotecários nos EUA (\%) - 1970-2010 Fonte: Financial Crisis Inquiry Commission (2011)

Os bancos comerciais, por sua vez, precisaram reinventar-se para não perder volume de negócios ou mesmo tornar-se insolváveis. Uma das formas de reinvenção foi a ênfase em receitas derivadas de tarifas e encargos, em oposição a receitas provenientes da diferença entre os juros pagos aos prestamistas (os depositantes do banco) e os juros obtidos dos prestatários (empresas e famílias que solicitam empréstimo) (DYMSKI, 2009; DOS SANTOS, 2009). A securitização de hipotecas serviu a esse propósito: com a securitização, o banco não mantém o empréstimo concedido no seu balanço contábil, transferindo esse ativo para um investidor em troca de encargos e tarifas. No caso dos Estados Unidos, esse investidor foi e continua sendo, em grande medida, as empresas semi-públicas (ou empresas patrocinadas pelo governo, em inglês Government-sponsored enterprises) Fannie Mae e Freddie Mac já mencionadas. Após adquirir um portfólio de hipotecas, estas empresas emitem títulos (inicialmente Residential Mortgage-backed Securities ou RMBS) lastreados pelo fluxo de renda gerado pelas hipotecas, e esses títulos são adquiridos por investidores institucionais (fundos de pensão, seguradoras, fundos de investimentos, fundos de hedge) americanos e estrangeiros. $\mathrm{O}$ resultado final dessa metamorfose foi o crescente financiamento de hipotecas através do mercado financeiro (GREEN \& WACHTER, 2005; GOTHAM, 2009; IMMERGLUCK, 2009), registrado na Figura 1 principalmente pelo crescimento de hipotecas com fonte de recursos proveniente das GSE (Fannie Mae e Freddie Mac, fundamentalmente).

O processo de securitização - ou seja, a transformação de contratos de empréstimo imobiliário em títulos (securities) de alta liquidez - não deve ser interpretado como um fenômeno que, de per si, amplificaria significativamente os riscos de crises financeiras, embora seja correto afirmar 
que, ao engendrar uma sincronização mais acurada entre as oscilações do mercado financeiro e as do mercado imobiliário, a securitização de hipotecas potencializa as chances de uma crise localizada adquirir dimensões sistêmicas. Mas a forma como a securitização desenvolveu-se nos Estados Unidos, cujos traços mais importantes precisam ser entendidos contra o pano de fundo da financeirização da economia americana, multiplicou os riscos vinculados à produção do ambiente construído, além de transferi-los, como a última crise tornou evidente, para os elos mais vulneráveis da cadeia de crédito - as famílias de minorias étnico-raciais (afro-americanos e descendentes de latino-americanos) que em muitos casos foram despejadas de suas casas. É pertinente explorar algumas das facetas do desenvolvimento do sistema de crédito habitacional ao longo dos anos 1990 e 2000 para iluminar os contornos mais salientes da transformação em pauta.

\section{O CRESCIMENTO DOS EMPRÉSTIMOS SUBPRIME: segregação racial e especulação financeira nos anos 1990 e 2000}

Uma série de fatores de complexa elucidação favoreceram, nos anos 1990 e 2000, um crescimento expressivo na oferta de crédito imobiliário a famílias de baixa renda nos Estados Unidos.

Um desses fatores reside no afã dos bancos comerciais em conquistar novas clientelas à medida que a competição acirrava-se, na esteira da onda de fusões e aquisições dos anos 1980. Isso combinou-se com inovações financeiras e tecnológicas capacitando instituições financeiras a formular instrumentos de investimento cada vez mais complexos. Um desses instrumentos, que posteriormente ganhou notoriedade com o estouro da bolha imobiliária, foram as Obrigações Hipotecárias Colateralizadas (em inglês, Collateralized Mortgage Obligations, CMO). Os CMO são instrumentos que permitem a segmentação de um conjunto (pool) de hipotecas em fatias de risco adequadas a diferentes perfis de investimento. Essas fatias recebem diferente avaliação pelas agências de avaliação de risco, e possuem perfis diferentes de rentabilidade e maturidade. Ao longo dos anos 1990, não apenas as agências com apoio governamental Fannie Mae e Freddie Mac, mas também instituições financeiras privadas passaram a ofertar títulos como os CMO (ver emissões privadas na Figura 1).

Uma segunda causa repousa sobre o crescimento da demanda por esse gênero de títulos, o que reflete, em grande medida, problemas sistêmicos da economia americana que ganharam maior proeminência a partir do final da década de 1990. Esse crescimento da demanda por títulos financeiros teve origens internas e externas. Internamente, está ancorado na enorme liquidez existente na economia americana, que se origina pelo menos em dois fenômenos concomitantes: por um lado, a existência de massas de capitais excedentes que não encontram escoadouros lucrativos na produção, principalmente em virtude das dificuldades de acumulação a partir do final da década de 1990, quando um ciclo de recuperação das taxas de lucro e das taxas de investimento em capital fixo foi interrompido com o estouro da bolha das empresas de tecnologia e informação (BRENNER, 2004; McNALLY, 2009; 2011); por outro, o aumento dramático da desigualdade social ao longo do período neoliberal, que acarretou uma concentração acentuada da riqueza monetária nas mãos de indivíduos, reforçando a demanda por títulos financeiros. Mas há também um componente externo de igual importância nessa equação: os recrudescentes déficits no balanço de pagamentos dos Estados Unidos desde a década de 1980 inundaram a economia mundial de dólares. Em um cenário de alta instabilidade econômica mundial, muitos desses dólares retornaram para os Estados Unidos nas mãos de investidores estrangeiros desejosos de um refúgio seguro para seus capitais, incrementando, assim, a demanda por títulos financeiros para além dos títulos do Tesouro americano.

Esse cenário culminou na bolha imobiliária da década de 2000 - um prosseguimento da bolha no mercado de ações que estourou no fim da década de 1990. Confrontados com uma demanda crescente por títulos lastreados por hipotecas, e desinibidos pela negligência das agências governamentais em supervisionar os padrões de oferta do crédito habitacional, bancos e outras instituições 
financeiras relaxaram progressivamente seus padrões de avaliação de risco, oferecendo hipotecas cada vez mais "exóticas" (com baixo ou nenhum pagamento de entrada, taxas de juros variáveis, etc). Essas hipotecas eram organizadas em bloco e, de modo cada vez mais acelerado, transformadas em títulos a serem vendidos para investidores de todas as partes do mundo (ver Figura 2). É nesse contexto que ocorre uma transformação significativa nos padrões de segregação racial nos Estados Unidos, um aspecto pouco mencionado em análises da crise econômica. Por muitas décadas, trabalhadores negros e pertencentes a outras minorias étnico-raciais ficaram excluídos das redes de crédito (habitacional ou ao consumidor) em um processo que ficou conhecido como redlining. A crescente procura por títulos como os $\mathrm{CMO}$ levou os bancos e outras entidades de empréstimo hipotecário a oferecer crédito a um custo exorbitante - em juros e tarifas administrativas - a essas mesmas minorias antes excluídas. Diversos estudos recentes mostram a maior propensão de famílias de minorias étnico-raciais a receber empréstimos hipotecários com custos altíssimos, mesmo quando seu histórico de crédito tornariam-nas aptas a obter um empréstimo de baixo custo (prime) (NEWMAN, 2009; SASSEN, 2008; GOTHAM, 2009; IMMERGLUCK, 2011; DYMSKI, 2009). Não é uma surpresa, logo, que são essas famílias vítimas de empréstimos predatórios que estão, desde 2007, inflando as estatísticas de despejo em todo o país. Esses fenômenos sugerem um abrangente processo de expropriação financeira operando no núcleo do capitalismo avançado (HARVEY, 2005; LAPAVITSAS, 2009).

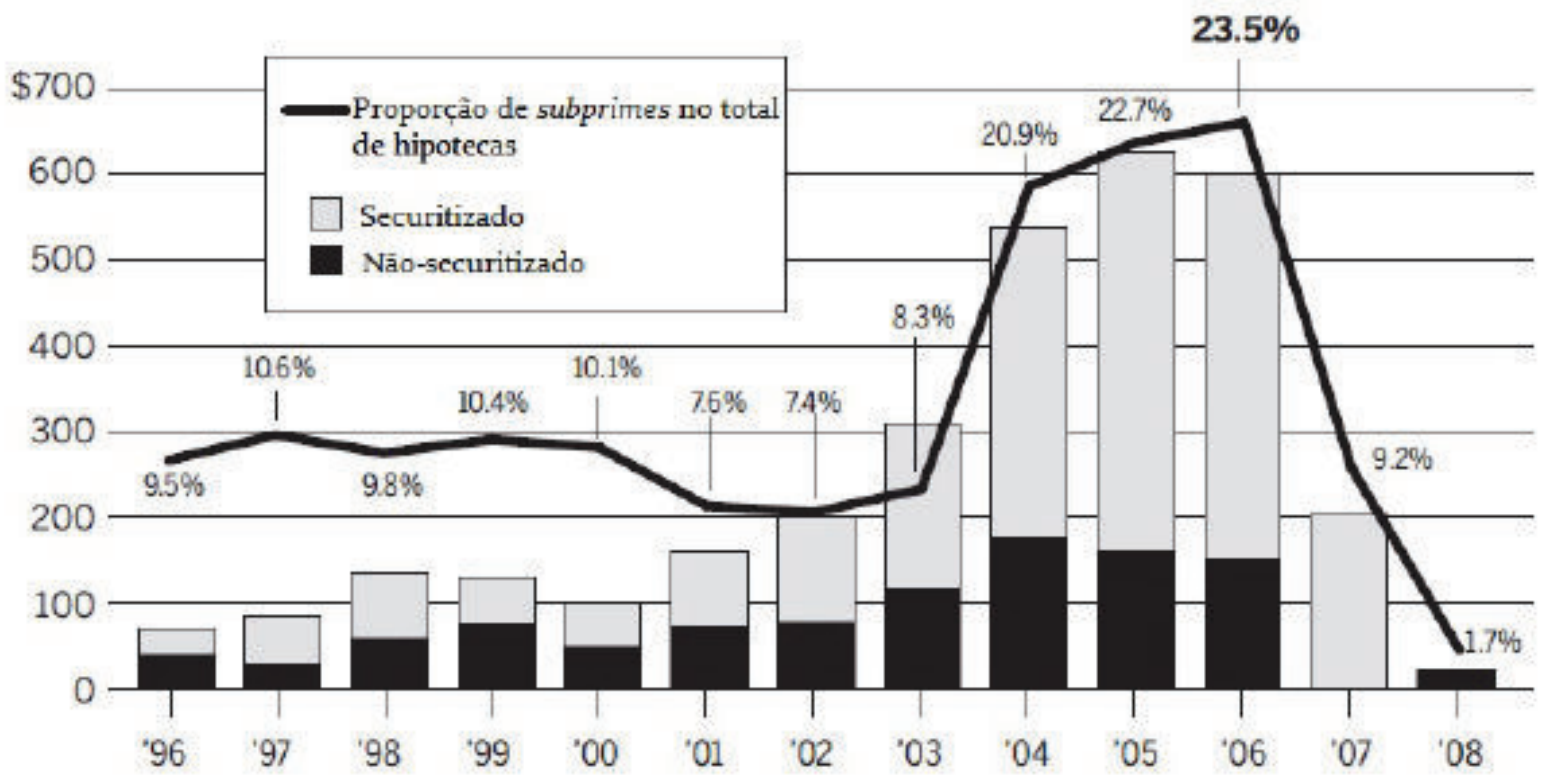

Figura 2 - Contratos de hipoteca de alto risco (subprime) nos EUA (em bilhões de dólares) - 1996-2008. Fonte: Financial Crisis Inquiry Commission (2011).

Para finalizar esse item, é necessária uma breve observação acerca do tratamento comumente dado à crise econômica de 2007-2009 - ainda que o foco desse trabalho não seja a crise em si. Embora seja correto apontar o papel-chave do setor imobiliário em desencadear a crise, é preciso entender esta última como uma expressão de múltiplas contradições no seio da acumulação capitalista que não se limitam à operação dos mercados imobiliários, mas dizem respeito a uma expansão insustentável das cadeias de crédito a partir de 2000-2001. Nesse sentido, é sintomático o fato de que não apenas as famílias tiveram um incremento exponencial no nível de endividamento ao longo da década, mas, com maior intensidade ainda, as instituições financeiras atingiram um nível de alavancagem (endividamento) sem precedentes (BLACKBURN, 2008; FOSTER \& MAGDOFF, 2009; McNALLY, 2009; GOWAN, 2009; LAPAVITSAS, 2009; HARVEY, 2010; DUMÉNIL \& LEVY, 2011). 


\section{CONSIDERAÇÕES FINAIS}

Ao longo desse trabalho, expusemos, através de uma breve análise das mudanças no sistema de crédito habitacional dos Estados Unidos, alguns dos pontos decisivos de uma transformação fundamental na relação entre o sistema de crédito e a produção e consumo do ambiente construído. A primeira parte contrastou o modelo de crédito habitacional americano que prevaleceu entre 1930 e 1980 - um sistema ancorado em bancos comerciais e entidades de poupança e empréstimo (S\&L) de caráter eminentemente regional - com o crescente financiamento habitacional através do mercado de capitais, dos anos 1980 em diante, como resultado do crescimento progressivo na emissão de títulos lastreados por hipotecas como os Residential Mortgage-backed Securities (RMBS) e os Collateralized Mortgage Obligations (CMO). Foi observado o papel do Estado em implementar reformas favoráveis a esse resultado já no final da década de 1960. Na seção seguinte foram identificadas algumas das forças responsáveis pelo incremento da oferta de crédito imobiliário de alto risco entre o final da década de 1990 e boa parte da década de 2000. Observou-se que a expansão inaudita do crédito imobiliário precisa ser entendida no contexto das dificuldades enfrentadas pela economia americana desde o final da década de 1990, o que alimentou uma vigorosa demanda por títulos de maior rentabilidade e baixo risco (embora na verdade se tratassem de títulos de alto risco, a maioria dos investidores seguiu as orientações das agências de avaliação de risco, que classificavam sistematicamente esses ativos como de baixo risco). Além disso, esse período de expansão desenfreada do crédito imobiliário alterou a forma pela qual a segregação racial historicamente operou no país. Antes sistematicamente excluídos de qualquer empréstimo por canais formais, minorias étnico-raciais tornaram-se alvo de empréstimos predatórios que engendraram um expressivo processo de expropriação financeira.

As mudanças aqui assinaladas explicitam uma tendência inequívoca à metamorfose do ambiente construído em um título financeiro de maior liquidez cujo preço é definido pela rentabilidade que é capaz de gerar. Esse é um fenômeno associado - não apenas nos Estados Unidos - ao avanço do neoliberalismo como modelo norteador de políticas públicas e à capacidade do Estado de gerar um ambiente regulatório e institucional consentâneo à securitização. A fim de abordar essa transformação, foi examinado o sistema de crédito habitacional americano. Mas a securitização de hipotecas é apenas uma das formas através das quais o ambiente construído foi suficientemente flexibilizado de modo a satisfazer a demanda de investidores financeiros por ativos líquidos e rentáveis. É pertinente considerar outros instrumentos como expressões desse mesmo processo se quisermos formular uma interpretação mais abrangente acerca do significado da financeirização do ambiente construído urbano. Um exemplo claro disso são os fundos de investimento imobiliário, que experimentaram um crescimento acelerado em diversos países no mesmo período que recebeu ênfase no presente trabalho (GOTHAM, 2006). Os mecanismos que governam o funcionamento desses fundos são relativamente simples: o fundo investe em empreendimentos imobiliários geradores de um fluxo de renda por determinado período de tempo ou indefinidamente; o cotista obtém, com a aquisição da cota, o direito a um rendimento futuro gerado por esses empreendimentos, proporcional à alíquota da qual é proprietário, e o preço da cota consiste na capitalização desse rendimento futuro - o que significa que incrementos nos aluguéis que lastreiam as cotas resultam em "ganhos de capital" para os cotistas. Até mesmo ações e debêntures emitidas por incorporadores imobiliários podem ser encarados de forma semelhante: são ativos que compartilham com os mencionados anteriormente a característica de conferir, ao adquirente, um direito aos rendimentos futuros gerados pela reestruturação do ambiente construído urbano, operando, assim, como uma forma de capital fictício, nos termos de Harvey (1999). Todos esses instrumentos forjam nexos sólidos entre a captura da renda do solo urbano na escala local e a intricada arquitetura do sistema financeiro internacionalizado instituído no período neoliberal. Mais do que nunca, a transformação das metrópoles contemporâneas está atrelada à sua capacidade de gerar uma rentabilidade atrativa a investidores financeiros. 
Um último comentário possui pertinência na discussão em pauta. É inegável que a financeirização, aqui ilustrada na transformação na maneira através da qual a produção e o consumo do ambiente construído urbano é financiada, tem raízes em uma alteração significativa no equilíbrio de forças de classe que predominou no capitalismo pós-guerra (DUMÉNIL \& LEVY, 2001; 2004; 2011; HARVEY, 2005). Mas a financeirização não deve ser interpretada unicamente como uma "dominação" ou "primazia" do setor financeiro sobre o restante da economia. Esse gênero de abordagem transmite a ideia - mesmo que involuntariamente - de que o setor não-financeiro reproduz-se à margem de práticas financeirizadas. Haveria uma externalidade entre o setor financeiro (onde a financeirização se desenvolve) e o setor produtivo (subjugado pelo setor financeiro). A financeirização, porém, abrange uma pletora de práticas que permeiam as operações de empresas não-financeiras, dos governos e o cotidiano de diferentes grupos sociais (KRIPPNER, 2005; LANGLEY, 2008), e essa complexidade de práticas "financeirizadas" deve ser levada em conta para avançar o entendimento dessa etapa do capitalismo. Foi intenção desse trabalho contribuir modestamente nessa direção ao lançar luz sobre uma das dimensões em que a financeirização manifesta-se no capitalismo atual.

\section{REFERÊNCIA BIBLIOGRÁFICA}

AALBERS, M. The financialization of home and the mortgage market crisis. Competition \& Change, Vol. $12, \mathrm{n}^{\mathrm{o}} .2$, p. 148-166, 2008.

AALBERS, M. The sociology and geography of mortgage markets: reflections on the financial crisis. International Journal of Urban and Regional Research, Vol. 33.2, p. 281-290, 2009.

BLACKBURN, R. The subprime crisis. New Left Review, Vol. 50, p. 63-106, 2008.

BRENNER, R. New boom or new bubble? The trajectory of the US economy. New Left Review, Vol. 25, pp. 57-99, 2004.

DOS SANTOS, P. On the content of banking in contemporary capitalism. Historical Materialism, $\mathrm{n}^{\mathrm{o}} .17$, p. 180-213, 2009.

DUMÉNIL, G \& LEVY, D. Costs and benefits of neoliberalism: a class analysis. Review of International Political Economy, Vol. 8.4, p. 578-607, 2001.

DUMÉNIL, G \& LEVY, D. Neoliberal income trends: wealth, class, and ownership in the USA. New Left Review, no ${ }^{\circ}$ 30, p. 105-133, 2004.

DUMÉNIL, G \& LEVY, D. The crisis of neoliberalism. Cambrigde, MA: Harvard University Press, 2011. DYMSKI, G. Racial exclusion and the political economy of the subprime crisis. Historical Materialism, $\mathrm{n}^{\circ} .17$, p. 149-179, 2009.

FINANCIAL CRISIS INQUIRY COMMISSION. The financial crisis inquiry report: final report of the national commission on the causes of the financial and economic crisis in the United States. Washington, D.C., 2011.

FOSTER, J. B. \& MAGDOFF, F. The great financial crisis: causes and consequences. New York: Monthly Press Review, 2009.

GOTHAM, K. F. The secondary circuit of capital reconsidered: globalization and the US real estate sector. The American Journal of Sociology, Vol. 112, nº. 1, p. 231-75, 2006.

GOTHAM, K. F. Creating liquidity out of spatial fixity: the secondary circuit of capital and the subprime mortgage crisis. International Journal of Urban and Regional Research, Vol. 33.2, p. 355-71, 2009.

GOWAN, P. Crisis in the heartland. New Left Review, Vol. 55, p. 5-29, 2009.

GREEN, R. \& WACHTER, S. The American mortgage in historical and international context. Journal of Economic Perspectives, Vol. 19, nº. 4, p. 93-114, 2005.

HARVEY, D. The urban experience. Baltimore: John Hopkins University Press, 1989.

HARVEY, D. The limits to capital. New York: Verso, 1999.

HARVEY, D. A brief history of neoliberalism. New York: Oxford University Press, 2005. 
HARVEY, D. The enigma of capital and the crises of capitalism. New York: Oxford University Press, 2010. IMMERGLUCK, D. Foreclosed: high-risk lending, deregulation, and the undermining of America's mortgage market. New York: Cornell University Press, 2009.

IMMERGLUCK, D. The local wreckage of global capital: the subprime crisis, federal policy and high foreclosure neighborhoods in the US. International Journal of Urban and Regional Research, Vol. 35.1, p. 130-146, 2011.

KRIPPNER, G. R. The financialization of the American economy. Socio-economic Review, Vol. 3, pp. 173-208, 2005.

LANGLEY, P. Financialization and the consumer credit boom. Competition \& Change, Vol. 12, nº 2, p. 133-147, 2008.

LAPAVITSAS, C. Financialized capitalism: crisis and financial expropriation. Historical Materialism, $\mathrm{n}^{\circ}$. 17, pp. 114-148, 2009.

McNALLY, D. From financial crisis to world slump: accumulation, financialisation, and the global slowdown. Historical Materialism, $\mathrm{n}^{\circ}$. 17, pp. 35-83, 2009.

McNALLY, D. The global slump: the economics and politics of crisis and resistance. Oakland: PM Press, 2011. NEWMAN, K. Post-industrial widgets: capital flows and the production of the urban. International Journal of Urban and Regional Research, Vol. 33.2, pp. 314-42, 2009.

SASSEN, S. Mortgage capital and its particularities. Journal of International Affairs, Vol. 62, $\mathrm{n}^{\mathrm{o}}$. 1, p. 187-212, 2008.

WALKER, R. A theory of suburbanization: capitalism and the construction of urban space in the United States. In: DEAR, M. \& SCOTT, A. (org.). Urbanization and urban planning in capitalist society. London: Methuen, 1981.

Trabalho enviado em dezembro de 2011 Trabalho aceito em janeiro de 2011 